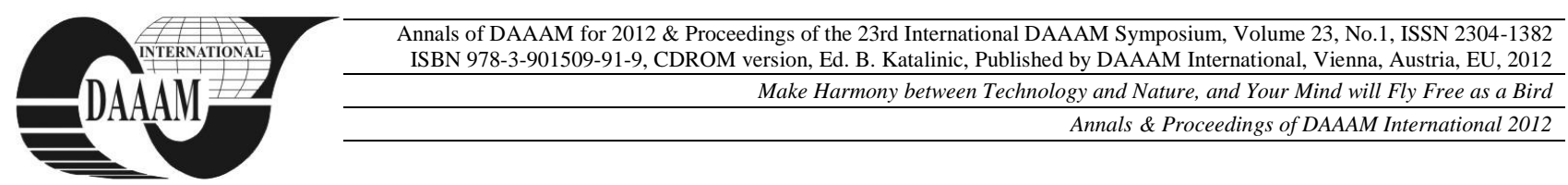

\title{
DIFFERENT TYPES OF INNOVATIONS MODELING
}

\author{
NICOLOV, M[irela] \& BADULESCU, A[lina] D[aciana]
}

\begin{abstract}
In the present paper we present a model for different types of innovations for different types of companies: small, medium and big one. After a brief review of existing innovation models in the literature, are presented different types of innovations: product innovations, process innovations and product and process innovations from small, medium and big companies in Romania. It is done a forecasting for the next 20 years too. It's a new study based on data that were taken in Romania only after 2000.

Keywords: Innovation, Product Innovations, Process Innovations, Product and Process Innovations, Measurement of economic growth.
\end{abstract}

\section{INTRODUCTION}

In this paper we examine some types of innovations from small, medium, and big companies in Romania, between 2000 and 2008. After a brief review of existing innovation models in the literature, we present different types of innovations: product innovations, process innovations, respectively product and process innovations from these companies in Romania. It's a new study based on data that were taken in Romania only after 2000.We want to create a model to describe these types of innovations in Romania. The limitation of this model appear because there is a small number of values reported by the National Institute of Statistic from Bucharest (from www.insse.ro). In the future we want to create an econophysics model to describes the evolution of this sector (research development and innovation sector-RDI sector).

\section{LITERATURE CRITICAL OVERVIEW}

Innovation is based on the results of new technologies, technological development, new combinations of existing technology or knowledge obtained using other company [1].

\subsection{Models of innovation}

Models of innovation are closely related to new scientific discoveries and fundamental research in applied research, technical applications. In practice are introducing scientific discoveries, ie the introduction of new products, processes and services.

These new innovative scientific and technical achievements, resulting from production processes are transformed into market able goods. Innovation process evolves starting with the 1950-1960 period from a linear model to model more complex integrated and characteristic period 1980-1990 [2]. Rothwell identified five generations of innovation models that represent stages in the evolution of economic thought and economic realities of the community of scientists [2].

Marinova and Phillimore presented in the book: "The International Handbook of Innovation," a chapter with the following types of innovation models [3]:(1) Firstgeneration of innovation model the black box model;(2) A second generation - linear models (including "technology push" and "need pull");(3) The third generation - interactive models (including models of coupling and integrated models);(4)The fourth generation - models of innovation systems (including networks and national innovation systems);(5) The fifth generation and evolutionary models;(6) The sixth generation innovative models of type Milieu.

We will make a parallel between the two types of innovation models that are in literature as they appear in the works of Le Corre and Mischka since 2006 and in that one of Marinova and Phillimore in The International Handbook of Innovation edited by Shavinina in 2003, in different presentations.

\section{First generation of innovation model}

The first generation of innovation model are linear models of "technology push". These are characteristic of the years 1950-1960. Innovation process has sequential phases, which are: Fundamental research $\rightarrow$ Design $\rightarrow$ Manufacturing $\rightarrow$ Marketing $\rightarrow$ Sales [4].

The first generation of innovation model is considered to be the Black Box. In 1957, Solow has studied the evolution of the U.S. economy by studying the influence of factors of production in the U.S. RDI system during 1909-1949. 90\% of results were attributed to technological change. This phenomenon present the invisibility of what happens to investments in RDI sector and thus the first innovation model was called "black box". The black box was borrowed from cybernetics, where is considered that the innovation process is not important. Are important only the parameters which are input and output data's of this model [3].

\section{Second generation of innovations model.}

Second generation of models are models of "market pull" which occurred during 1960-1970 and are all linear. Process innovation satisfy the consumer demands. Phases of the "market pull" model are: RDI $\rightarrow$ Manufacturing $\rightarrow$ Market requirements $\rightarrow$ Sales [4]. Second generation of models, respectively linear models including "Technology push" and " Need pull" are vision from 
Marinova and Phillimore [4]. Between 1980-1990 scientists have been interested in what's in the black box of the first generation models. They were interested in specific processes that have been generated by new technologies and knowledge required by new technologies. Innovation was seen as a step by step process whose market activities are adopted. The first linear model of innovation called "Technology push" model is very close to "science push". "Basic scientific discoveries lead to technological breakthroughs leading to the introduction of new products and processes on the market" [3].

The first linear model of innovation involves the following steps: Basic sciences $\rightarrow$ Applied sciences and engineering $\rightarrow$ Production $\rightarrow$ Marketing $\rightarrow$ Sales.

The line "Need pull" or "Market Driven" was developed not long after "Technology push" model to recognize the importance of market demand and supply technology to potential customers. It makes the following statement: causes innovations to market demand. The sequence is based on the following steps: Market $\rightarrow$ Technology $\rightarrow$ Production $\rightarrow$ Real Estate Development.

\section{The third generation of innovation models}

The third generation of innovation models are models of innovation "coupling" can be considered as a combination of models "technology push" and "market pull". This model is based on an interactive process that focuses on the effects of feedback between phases of market research and previous linear models. Innovation process "coupling" is sequential and can be divided into distinct phases and dependent on each other. Phases interact through feedback to previous stage. This model implies that suppliers and customers should be closely "coupled" in product development teams [4].The third generation of innovation models are interactive models (which include coupling models and integrated models)[4]. The third innovation model correspond to the innovation process, which can be considered as a communication complex network, intra and extraorganizational, linking together various individual functions, the scientific community and technology market.

Stages of the third generation model are:

1. New needs $\rightarrow$ ideas and new concepts $\rightarrow$ new technological capabilities;

2. New needs $\rightarrow$ needs of society and market $\rightarrow$ technologies and advanced production techniques;

3. New needs $\rightarrow$ Development / Production/Marketing \& Sales /Market $\rightarrow$ Technologies and advanced production techniques.

\section{The fourth generation of innovation model}

The fourth generation of models are called functionally integrated innovation models. Occurred during 1980-1990 and is characterized by integration and product development in parallel and simultaneously. These models use product development models, as they are used by Japanese automobile industry and electrical products where functional integration of activities of different internal departments are throughout the innovation process. They achieved integrating suppliers, customers and partners in the development process. Integration within the firm takes place upstream with key suppliers and downstream clients on company products are applicants. Models of the fourth generation are based on complex iterations feedback loops and reciprocal relationships between marketing, RDI, operations, distribution [5].

\section{Fifth generation of innovation models}

The fifth generation of models first appear in the 90s, is the integration processes and innovation systems in the network. In these models, organizations form, networks of innovators includes key suppliers, customers, other industrial companies, universities. They have to use a combination of technologies to solve highly complex problems of new products. Network innovation involves modern simulation tools and systems, expert design and rapid prototyping, leading the digitization process innovation. In the networked innovation systems development teams are organized along which addresses the creation of new products based on the concept of concurrent engineering or simultaneous [6]. The fifth generation innovation is a response to high levels of risk and uncertainty of innovation. This model generate the using in the companies the best practices and organizational innovations that allow a better flexibility and sensitivity in relation to unpredicTab. and turbulent markets. The fifth generation of innovation models include evolutionary models [3]. This new approach explains that innovation, by definition, involves change, and decisions are made not only for price. The selection process must take into account the decisions and the environment.

After the Second World War, governments have consistently funded their orientation towards research. In terms of the model of development is emphasized that the process and results are important.RDI and a 1996 OECD report recommends governments to increase the number of innovators companies. It is a model in which different participants interact to produce innovations.

\section{The sixth-generation innovation models}

The sixth-generation of innovation models is the "Technology Innovation" is based on modeling, simulation, virtual reality, extracting data from databases, artificial intelligence, rapid prototyping etc. To analyze a large number of customers which used techniques for obtaining data on several market segments and multiple service offerings. Innovation in this model is designed for technology innovation and innovation are closely related to technological innovation that enable innovation and manufacturing operational technologies implementing innovation. Advantages of using these top technologies shown in the application of simulation environments used to test the destruction of automotive designers made computer. They offer significant advantages automobile manufacturers by reducing development time and costs, slow production to avoid safety testing of prototypes early in the design process and costs for their physical destruction [13]. 
A sixth-generation innovation models include innovative models of type Milieu [3].

Since 1970 much literature has dealt with issues of regional groups to increase innovation and high technology. The innovative environment states that "innovation comes from a combination of general creative know-how and competence" and "territorial organization is an essential part of the creative process techno-economic" [3]. Innovation seems to be a localized phenomenon intrinsically territorial point of view, which is dependent on the specific location of resources linked to certain places and impossible to replicate elsewhere.

What becomes clear from this overview of six generations of innovation models is that we realize that studying innovation is a complex process and difficult for corporate or public policy. Innovation models have moved concept in terms of firm control (CD, management, marketing, finance, etc.) to external factors of the company, such as networks of companies, government institutions and policies, culture and geography. The models presented here provide the basics of the explanation of the phenomenon of innovation. Each model is a simplification of reality.

Can identify innovation processes of the sixth generation processes if is running the creativity and ideas shared between various innovators inside and outside the company, if simulation, optimization modeling and diffusion of the creation of new products and services and the processes by which they are produced and delivered $[3 \div 13]$.

\subsection{Types of innovations}

Product innovation is the placing of a good or service new or significantly improved with respect to its characteristics, such as improved software, user-friendly introduction to elements, components or subsystems. Innovation must be new for the company, but need not be new to the industry or market $[1,14]$.

Process innovation corresponds to implementing a production process, a method of distribution or a new or significantly improved support activities. Innovation (new or improved) must be new for the company, but need not be new to the industry or market $[1,14]$.

\section{RESEARCH METHODOLOGY}

Research methodology is based on simulation data's on the types of innovations for the period 2000-2008. The studies presented here were performed on product innovations, process innovations and product and process innovations. It was studied different cases such as for small, medium and big companies. Data were taken from the site of the Bucharest National Statistics Institute from Tempo online database accessed in September 2012 (data's updated on 21/10/2010)[15].

The central objective of this study is to observe the types of innovations in Romania during 2000-2008. The main objective was to see if the real data in compliance or not a particular model, if that a particular regression.

\section{RESULTS}

The data used in this study are taken from the site of the Romanian National Statistics Institute, the database Tempo - online database updated 10/21/2010.

Types of innovations will be presented for different types of companies, for the class size and economic activities. Data refer only product innovators, process innovators and product and process innovators. Data refer also to small, medium and large companies[14,15].

\section{Product Innovations}

In small companies these values are $59.11 \%$ of total companies in Romania in 2002. The number of product innovations in 2004 was 266 which representing $56.36 \%$ of those registered in 2002, while in 2006 the value of product innovations increase to $62.86 \%$ of the value recorded in 2002. In 2008 the number of product innovations in the small companies increase to 1324 which represents $67.86 \%$ of the total recorded in 2008 .

In the medium companies, product innovations represent $29.55 \%$ of the total in 2002 . Value decreases from 172 in 2004 to 148 in 2006.Their value increased to 155. In 2008, the number of product innovations increased 2.76 times from the values recorded in 2002 and represents $24.4 \%$ of the total registered in 2008 .

In big companies, product innovations are $11.34 \%$ of those registered in Romania. This value decreases from 66 in 2004 to 40 in 2006 respectively to 151 in 2008. The product innovations registered in Romania, representing $7.74 \%$ of the total value registered in the country, but increased by 2.28 times from the value recorded in 2002 .

\section{Process Innovations}

In the small companies, the number of process innovations is only $48.67 \%$ of those registered in 2002 in Romania, their value increases in 2004 to $61.43 \%$ and in 2006 this value increased to $59.79 \%$ of process innovations registered in Romania. In 2008, the process innovations in Romania increased by 14.97 times the values recorded in 2002, from 201 registered in 20023010 in 2008

In the medium companies registered in Romania, the number of process innovations only increased from 138 recorded in 2002-343 in 2004 and 365 in 2006 because in 2008 their number to reach 868 , which we conclude that there was an increased of 6.28 times compared to 2002.

In the big companies, the number of process innovations in 2002 only $17.92 \%$ of the total number registered in that year in Romania. Although this value increases in 2004 to 74 121, the total registered in Romania, their value decreases from $17.92 \%$ to $10.06 \%$. In 2006 this value drops to 105, because in 2009 their value to increase by 2.71 times.

\section{Product and Process Innovations}

For Small Companies, the product and process innovations represent $53.27 \%$ of the total value registered in Romania in 2002, this value increases from 1581 to 2002-1829 in 2004 to 2477 in 2006, recorded in 2008 
respectively 2453 , value increased 1.55 times the figure recorded in 2002. For medium companies, product and process innovations in 2002 represents $29.25 \%$ of those registered in that year in Romania, ie 868 . These values increase by 1.26 times in 2004, of 1.49 times in 2006 and reach a value of 1044 in 2008, this value is $26.39 \%$ of those registered in Romania in that year and is 1.2 times higher than values in 2002. In big companies, product and process innovations registered in Romania in 2002 are $17.49 \%$ of the total registered in 2002. This value varies from 519 in 2002 to 538 in 2004, then decreases to 501 in 2006 and then in 2008 to arrive at a value of 449 which represents $86.51 \%$ of the values recorded in 2002 and represents $11.35 \%$ of the total registered that year in Romania.

Modeling and forecasting the product innovations, process innovations and product and process innovations respects the curves: $\mathrm{Y}=\mathrm{A} \cdot \mathrm{X}^{3}+\mathrm{B} \cdot \mathrm{X}^{2}+\mathrm{C} \cdot \mathrm{X}+\mathrm{D}$; Where $\mathrm{R}^{2}$ $=1$. The values for coefficients $\mathrm{A}, \mathrm{B}$ and $\mathrm{C}$ are listed in the tabs.1, 2 and 3 .

\begin{tabular}{|l|l|l|l|l|}
\hline & A & B & C & D \\
\hline TOTAL & 628 & -4180 & +8934 & -4969 \\
\hline Small companies & 488.1 & -3218 & 6774 & -3844 \\
\hline Medium companies & 110.6 & -755.5 & 1696 & -914 \\
\hline Big companies & 29.16 & -206.5 & 462.3 & -211 \\
\hline
\end{tabular}

Tab. 1. Process Innovations. Forecasting for the next 20 years. (authors calculus based on [12,13].)

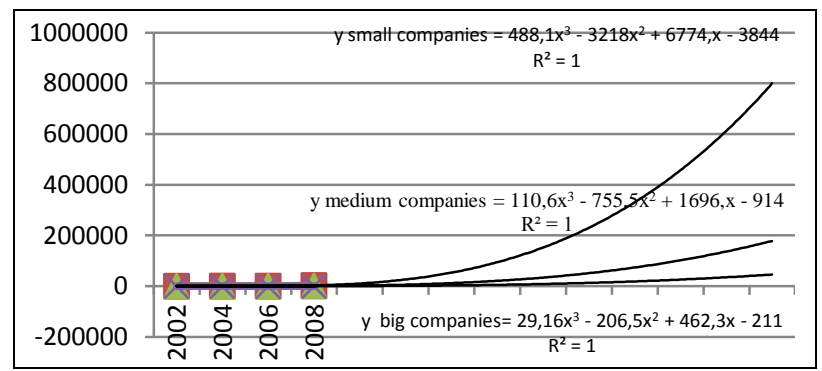

Fig.1. Process Innovations. Forecasting for the next 20 years. (authors calculus based on [12,13].)

\begin{tabular}{|l|l|l|l|l|}
\hline & A & B & C & D \\
\hline TOTAL & 201.6 & -1128 & 1863 & -355 \\
\hline Small companies & 131.3 & -717 & 1153 & -224 \\
\hline Medium companies & 47.16 & -267.5 & 448.3 & -56 \\
\hline Big companies & 23.16 & -144 & 261.8 & -75 \\
\hline
\end{tabular}

Tab. 2. Product Innovations, Forecasting for the next 20 years (authors calculus based on [12,13].)

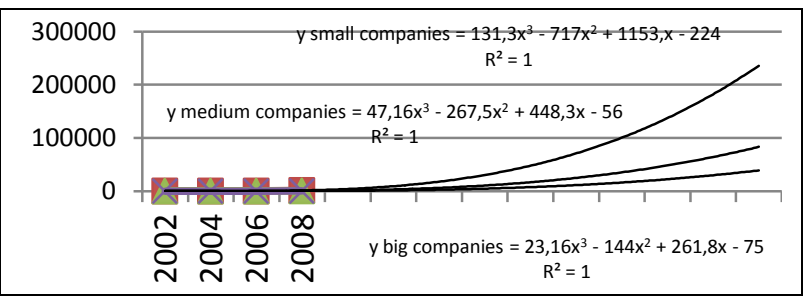

Fig.2. Product Innovations, Forecasting for the next 20 years (authors calculus based on [12,13].)

\begin{tabular}{|l|l|l|l|l|}
\hline & A & B & C & D \\
\hline TOTAL & -242.8 & 1618 & -2661 & 4254 \\
\hline Small companies & -177 & 1262 & -2299 & 2795 \\
\hline Medium companies & -72.66 & 425 & -540.3 & 1056 \\
\hline Big companies & 6.833 & -69 & 178.1 & 403 \\
\hline
\end{tabular}

Tab. 3. Product and Process Innovators, Forecasting for the next 20 years (authors calculus based on [12,13].)

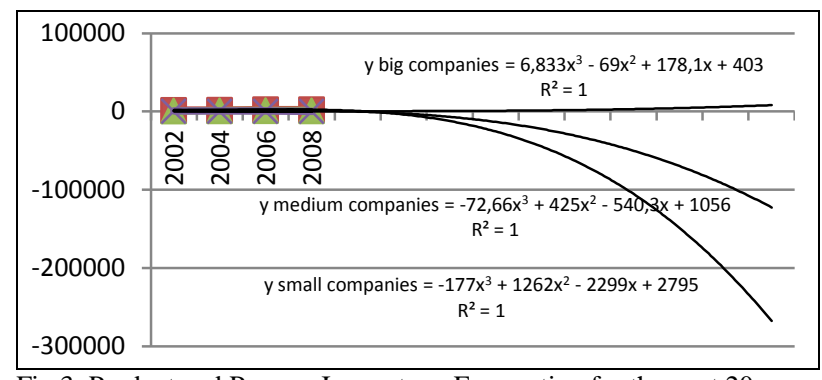

Fig.3. Product and Process Innovators, Forecasting for the next 20 years (authors calculus based on [12,13].)

\section{CONCLUSIONS}

In conclusion it may be noted that for all cases studied here: for Romania during 2000-2008, small, medium and big companies, product and process innovations in all cases is higher than of process innovations and product innovations. We can conclude from the present study that product innovations only and process innovations only are increasing phenomenon in the next 20 years for all types of companies: small, medium and big companies. But the process and product innovations are a decreasing phenomenon for small and medium companies. For big companies there is an increasing phenomenon for the next 20 years. The Romanian case belongs to the sixth-generation innovation models which is the "Technology Innovation"

\section{REFERENCES}

[1] ***, Statistical Yearbook of Romania(2010), Chapter 15. Enterprise activity, cap.13. Science Technology and Innovation, 2010

[2] Rothwell R. (1994), Towards the Fifth-generation Innovation Process, International Marketing Review, vol.11, No.1, pp.7-31,

[3] Marinova D., Phillimore J.,(2003), Models of innovation, in The International Handbook of Innovation, edited by Larisa V. Shavinina, Elsevier Science Ltd., p.44-53

[4] Le Corre A., Mischke G., (2006), The Innovation Game. A New Approach to Innovation Management and R\&D, Springer US, 2006

[5] Galanakis K., (2006) Innovation process, Make sense using systems thinking, Technovation, november, p.1222-1232.

[6] Dodgson, M., Gann D., Salter A.,(2008), The management of technological Innovation, Oxford University Press

[7] Gann, D. and Dodgson, M. , (2007), Innovation Technology: How New Technologies Are Changing The Way We Innovate, National Endowment for Science, Technology and the Arts, London

[8] Tushman M.L., Anderson P.,(1986), Technological Discontinuities and Organizational Environments, Adminstrative Science Quaterly, 31(2), p.439-465

[9] Fagerberg J., (2005), Innovation: A Guide to literature, pag.1-27, în The Oxford Handbook of Innovation, ed.by Ian Fagerberg, David C.Mowery and Richard R. Nelson, Oxford University Press, 2005

[10] Fagerberg J.,Godinho M.,(2005), Innovation and Catching up, pag.514-542, în The Oxford Handbook of Innovation, ed.by Ian Fagerberg, David C.Mowery and Richard R. Nelson, Oxford University Press, 2005

[11] Fagerberg Jan, Verspagen Bart, (2009), Innovation studies-The emerging structure of a new scientific field, Research Policy,no 38 , p.218-233

[12] http://www.insse.ro/cms/files/Anuar\%20statistic/13/13\%20Stiinta ,\%20tehnologie\%20si\%20inovare_ro.pdf , Accessed on: 2012-0912

[13] https://statistici.insse.ro/shop/index.jsp?page=tempo3\&lang=ro\&i nd=INO101A, Accessed on: 2012-09-12 